Proceedings of the XXIII Conference on Applied Crystallography, Krynica Zdrój, Poland, September 20-24, 2015

\title{
Structure of CaPs Coatings Electrophoretically Deposited on NiTi Shape Memory Alloy
}

\author{
K. DUDEK* AND T. GORYCZKA \\ University of Silesia, Institute of Materials Science, 75 Pułku Piechoty 1A, 41-500 Chorzów, Poland \\ The surface of NiTi shape memory alloys applied as long-term implants has been modified by protective calcium \\ phosphates $(\mathrm{CaPs})$ coatings, with the objective of improving the biocompatibility of this material. The calcium \\ phosphates such as hydroxyapatite $\mathrm{Ca}_{5}\left(\mathrm{PO}_{3}\right) \mathrm{OH}(\mathrm{HAP})$ and $\beta$-tricalcium phosphate $\beta$ - $\mathrm{Ca}_{3}\left(\mathrm{PO}_{4}\right)_{2}(\beta$-TCP) were \\ deposited by electrophoretic deposition. In order to improve the adhesion, the deposited samples were vacuum- \\ sintered at wide range of temperature from $500{ }^{\circ} \mathrm{C}$ to $1000^{\circ} \mathrm{C}$ for $2 \mathrm{~h}$. The studies revealed that applied sintering \\ conditions did not change the structure of CaPs. The coatings consisted of HAP with hexagonal structure $(P 63 / m)$ \\ and $\beta$-TCP with rhombohedral structure $(R-3 c)$. Changes in lattice parameters for CaPs coatings after deposition \\ and sintering were refined by the Rietveld method.
}

DOI: 10.12693/APhysPolA.130.1053

PACS/topics: 87.15.Tt, 87.68. $+\mathrm{z}, 61.10 . \mathrm{Nz}$

\section{Introduction}

The NiTi shape memory alloys (SMA), with its chemical composition near to equal-atomic, reveal interesting properties such as one- and two-way shape memory and superelasticity effects. Furthermore, these materials have good corrosion resistance and high biocompatibility. These features contributed to the many applications of these alloys in a wide range of medical fields [1]. However, the possibility of corrosion of NiTi SMA caused by long-term exposure of the human body environment, and related phenomenon of $\mathrm{Ni}$ ion release into tissue, still raises concerns as to application of these materials as long-term implants $[1,2]$. Therefore, it is justified to ensure a better corrosion resistance of NiTi SMA, which can be achieved by modifying the surface of alloy by applying biocompatible protective coatings. The surface of the NiTi alloys have been covered by polymers, ceramics or composites $[1,3,4]$. The coatings can also fulfill some additional functions. Thus, for example coatings based on CaPs such as HAP and $\beta$-TCP improve osseointegration [5]. However, most of techniques of surface engineering require the use of elevated temperatures, which in case of NiTi alloys may lead to the decomposition of alloy and therefore, it may result in vanishing of the shape memory and superelasticity effects. The surface modifications methods should also offer advantages, such as simplicity, repeatability, and low cost. These features are characteristic for the method of electrophoretic deposition (EPD) [6, 7].

In the presented work, in order to improve the corrosion resistance, the surface of the NiTi SMA was covered by biocompatible thin $\mathrm{TiO}_{2}$ film using passivation in autoclave $[4,8,9]$. Then, the HAP and $\beta$-TCP coatings were deposited on the passivated surface done with the

\footnotetext{
*corresponding author; e-mail: k.dudek@icimb.pl
}

use of EPD. In the next step, in order to improve the adhesion and consolidation, the deposited samples were sintered $[6,7]$. The main aim of this paper is focused on the structural studies of initial and deposited $\mathrm{CaPs}$ materials.

\section{Experimental}

The NiTi alloy with chemical composition of 50.6 at.\% $\mathrm{Ni}$ and 49.4 at.\% Ti (Memry, Belgium) was used as a substrate for CaPs coatings deposition. The samples were quenched to receive NiTi alloy in the $\beta$-phase $(B 2)$ at room temperature [4]. Next, they were polished mechanically, washed and passivated in autoclave $[4,8,9]$.

The powders of hydroxyapatite $\mathrm{Ca}_{5}\left(\mathrm{PO}_{4}\right)_{3} \mathrm{OH}$ (Sigma Aldrich) and $\beta$-tricalcium phosphate $\beta$-Ca $\left(\mathrm{PO}_{4}\right)_{2}$ (Sigma Aldrich) were used to prepare colloidal suspensions containing $0.1 \mathrm{wt} \%$ of powders in $99.8 \%$ ethanol (Avantor). In order to be suitable dispersed, the suspensions were put in a magnetic stirrer and then in an ultrasonic bath.

CaPs coatings were deposited on passivated NiTi alloy using EPD technique at ambient temperature. Constant voltages of $20-500 \mathrm{~V}$ for periods $30-120 \mathrm{~s}$ were applied. Uniform and thin coatings were obtained with deposition parameters $40 \mathrm{~V} / 120 \mathrm{~s}$ and $20 \mathrm{~V} / 60 \mathrm{~s}$ for HAP and TCP, respectively. Next, in order to improve the adhesion, the samples were vacuum-sintered at $500^{\circ} \mathrm{C}-1000^{\circ} \mathrm{C}$ for $2 \mathrm{~h}$. The measured thickness of layers, determined from the scanning electron microscope (SEM) observation done on the cross-sections, was $c a .2 .5 \mu \mathrm{m}$.

The morphology of the deposited coatings was observed with the use of a JEOL JSM-6480 SEM. The structure of materials before depositions was studied by X-ray diffraction (XRD) using X-ray diffractometer X'PertPro with monochromatized $\mathrm{Cu} K_{\alpha}$ radiation. The structure of the coated NiTi alloy was investigated using XRD pattern measured in the grazing incidence X-ray diffraction technique (GIXRD). The GIXRD patterns were collected at constant incidence angle of $0.2,0.3,0.5$, and $1.0^{\circ}$ at 
room temperature. The lattice parameters were refined by the Rietveld method using Rietica program. Reliability factors received from the XRD pattern refinement were lower than $8 \%$.

\section{Results and discussion}

For the electophoretic deposition, the colloidal suspensions of HAP and $\beta$-TCP powders were prepared. XRD measurements carried out for the powders showed its crystalline state (Figs. 1, 2, where black, red and green lines mean experimental, calculated and differential plot, respectively). For measured diffraction patterns diffraction lines were identified as belonging to phase $\mathrm{Ca}_{5}\left(\mathrm{PO}_{4}\right)_{3} \mathrm{OH}$ with hexagonal structure $(\mathrm{P} 63 / \mathrm{m})(\mathrm{PDF}-$ 2 , card no. 073-0293) as well as to the $\beta-\mathrm{Ca}_{3}\left(\mathrm{PO}_{4}\right)_{2}$ (PDF-2, card no. 09-0169) with rhombohedral structure $(R-3 c)$. The Rietveld method was used to refined lattice parameters of both phases. For the hydroxyapatite the lattice parameters were as followed: $a_{0}=b_{0}=$ 9.413(3) $\AA, c_{0}=6.878(7) \AA$ and for the $\beta$-tricalcium phosphate: $a_{0}=b_{0}=10.432(4) \AA, c_{0}=37.387(2) \AA$.

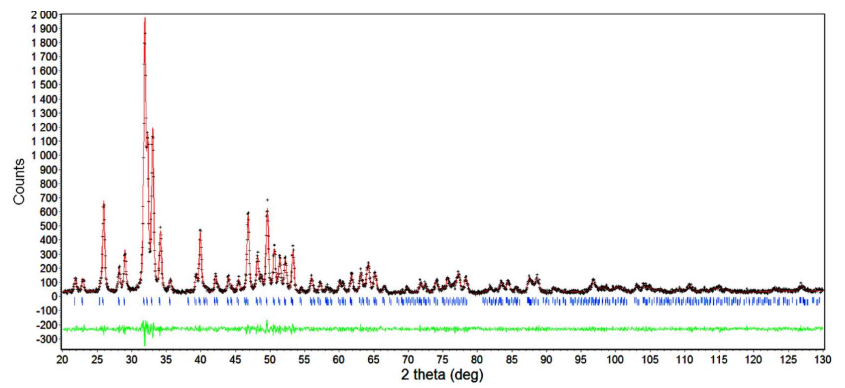

Fig. 1. X-ray diffraction patterns fitted with the Rietveld refinement for the HAP powder.

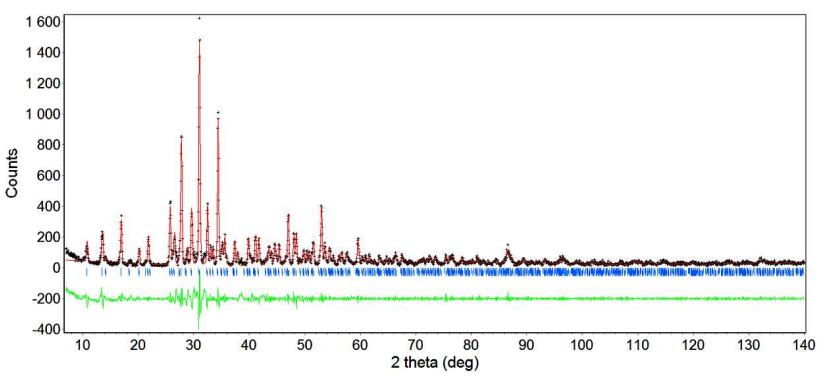

Fig. 2. X-ray diffraction patterns fitted with the Rietveld refinement for the $\beta$-TCP powder.

The deposition process carried out at $40 \mathrm{~V} / 120 \mathrm{~s}$ and $20 \mathrm{~V} / 60 \mathrm{~s}$ resulted in forming hydroxyapatite and $\beta$ tricalcium phosphate coatings [9], respectively. Next the samples deposited at these parameters were vacuumsintered. The microstructure of the coatings after the heat treatment at the highest applied temperatures is illustrated by Fig. 3. The obtained HAP layers were homogeneous, dense and crack-free (Fig. 3a). The TCP particles spread on the surface heterogeneously form larger agglomerates (Fig. 3b). Between $\beta$-TCP agglomerates a thin film consisting of $\mathrm{Ca}, \mathrm{P}$, and $\mathrm{O}$ was formed during the electrophoretic deposition process [9].
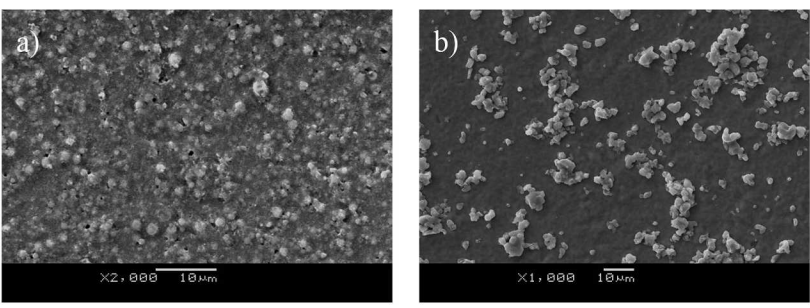

Fig. 3. SEM images observed for HAP coatings deposited at $40 \mathrm{~V} / 120 \mathrm{~s}$ and sintered at $900^{\circ} \mathrm{C} / 2 \mathrm{~h}$ (a) and $\beta$-TCP deposited at $20 \mathrm{~V} / 30 \mathrm{~s}$ and sintered at $1000^{\circ} \mathrm{C} / 2 \mathrm{~h}(\mathrm{~b})$.

TABLE I

Lattice parameters of HAP and $\beta$-TCP refined from the Rietveld refinement.

\begin{tabular}{c|c|c}
\hline \hline & \multicolumn{2}{|c}{ Lattice parameters } \\
\cline { 2 - 3 } Material & $a_{0}[\AA]$ & $c_{0}[\AA]$ \\
\hline HAP ICDD 01-073-0293 & 9.4320 & 6.8810 \\
HAP powder & $9.413(3)$ & $6.878(7)$ \\
HAP after deposition at $40 \mathrm{~V} / 120 \mathrm{~s}$ & $9.401(1)$ & $6.896(5)$ \\
$\mathrm{HAP}$ coatings sintered at $500^{\circ} \mathrm{C} / 2 \mathrm{~h}$ & $9.402(2)$ & $6.896(2)$ \\
$\mathrm{HAP}$ coatings sintered at $600^{\circ} \mathrm{C} / 2 \mathrm{~h}$ & $9.403(5)$ & $6.896(5)$ \\
$\mathrm{HAP}$ coatings sintered at $700^{\circ} \mathrm{C} / 2 \mathrm{~h}$ & $9.409(3)$ & $6.898(3)$ \\
$\mathrm{HAP}$ coatings sintered at $800^{\circ} \mathrm{C} / 2 \mathrm{~h}$ & $9.418(2)$ & $6.889(1)$ \\
$\beta$-TCP ICDD 00-009-0169 & 10.4290 & 37.3800 \\
$\beta$-TCP powder & $10.432(4)$ & $37.387(2)$ \\
$\beta$-TCP after deposition at $20 \mathrm{~V} / 30 \mathrm{~s}$ & $10.432(4)$ & $37.398(3)$ \\
$\beta$-TCP coatings sintered at $800^{\circ} \mathrm{C} / 2 \mathrm{~h}$ & $10.329(7)$ & $38.079(2)$ \\
$\beta$-TCP coatings sintered at $900^{\circ} \mathrm{C} / 2 \mathrm{~h}$ & $10.313(4)$ & $38.098(4)$ \\
$\beta$-TCP coatings sintered at $1000^{\circ} \mathrm{C} / 2 \mathrm{~h}$ & $10.339(5)$ & $38.153(6)$
\end{tabular}

Results of the qualitative phase analysis revealed that applied sintering conditions did not cause decomposition of the hydroxyapatite and $\beta$-tricalcium phosphate coatings.

The differences in the lattice parameters refined for the initial CaPs powders, the CaPs coatings deposited on the NiTi substrate in comparison to one obtained for the coatings after sintering are presented in Table I. Due to the heat treatment increase of $a_{0}$ parameter refined for HAP coating, decrease of $a_{0}$, and increase of $c_{0}$ refined for TCP were observed. The sample GIXRD patterns registered for the coatings sintered at the highest applied temperatures are illustrated by Figs. 4 and 5 .

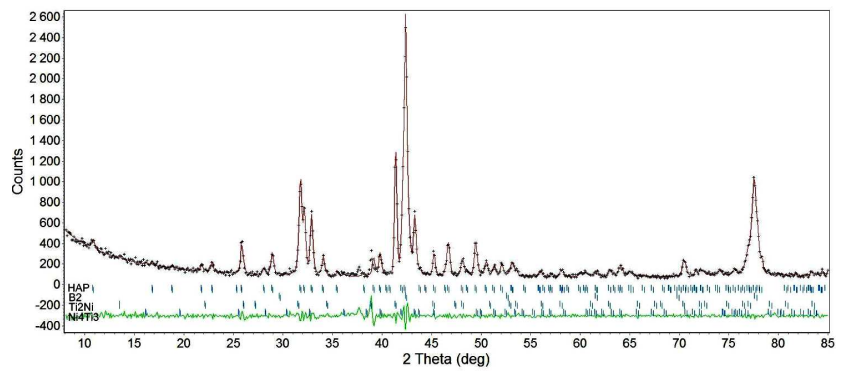

Fig. 4. Results of the Rietveld refinement carried out for the GIXRD patterns measured at incidence angle of $0.3^{\circ}$ for HAP coating created at $40 \mathrm{~V} / 120 \mathrm{~s}$ and sintered at $800^{\circ} \mathrm{C} / 2 \mathrm{~h}$ 


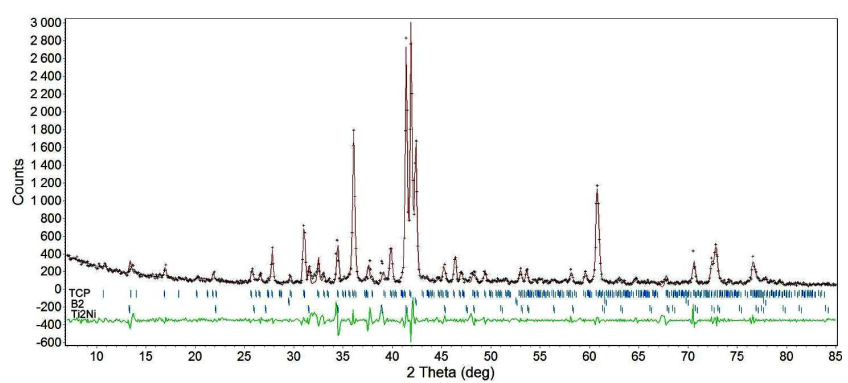

Fig. 5. Results of the Rietveld refinement carried out for the GIXRD patterns measured at incidence angle of $0.3^{0}$ for $\beta$-TCP coating created at $20 \mathrm{~V} / 30 \mathrm{~s}$ and sintered at $1000^{\circ} \mathrm{C} / 2 \mathrm{~h}$.

The studies revealed that applied sintering conditions resulted in a partial decomposition of the NiTi parent phase to the $\mathrm{Ti}_{2} \mathrm{Ni}$ with cubic structure $(F d-3 m)$ (PDF-2, card no. 72-0442). Moreover, additionally, the $\mathrm{Ni}_{4} \mathrm{Ti}_{3}$ phase with rhombohedral structure $(R-3 c)$ (PDF-2, card no. 39-1113) was identified.

\section{Conclusions}

In the present work, biocompatible HAP and $\beta$-TCP coatings were deposited on the passivated surface of the NiTi SMA. For the surface modification, an EPD technique was applied and next the samples were vacuumsintered at different temperatures. Despite the possibility of cracking due to sintering, the obtained coatings were crack-free. The studies revealed that the sintering resulted in changes of lattice parameters refined for the deposited CaPs $-a_{0}$ for HAP and both $a_{0}$ and $c_{0}$ for TCP. Use of high sintering temperatures did not cause decomposition of the hydroxyapatite and $\beta$-tricalcium phosphate coatings and the structure of the CaPs materials remained unchanged.

\section{References}

[1] T. Yoneyama, S. Miyazaki, Shape Memory Alloys for Biomedical Applications, Woodhead Publ., Cambridge 2009 .

[2] M. Es-Souni, H. Fischer-Brandies, Anal. Bioanal. Chem. 381, 557 (2005).

[3] F. Sun, K.N. Sask, J.L. Brash, I. Zhitomirsky, Coll. Surf. B 67, 132 (2008).

[4] K. Dudek, B. Szaraniec, J. Lelątko, T. Goryczka, Solid State Phenom. 203-204, 90 (2013).

[5] S.V. Dorozhkin, Prog. Biomater. 5, 2 (2012).

[6] R. Boccaccini, S. Keim, R. Ma, Y. Li, I. Zhitomirsky, J. R. Soc. Interface 7, 580 (2010).

[7] I. Zhitomirsky, Adv. Coll. Interface Sci. 97, 79 (2002).

[8] H. Morawiec, T. Goryczka, J. Lelątko, Z. Lekston, A. Winiarski, E. Rówiński, G. Stergioudis, Mater. Sci. Forum 636-637, 971 (2010).

[9] K. Dudek, M. Plawecki, M. Dulski, J. Kubacki, Mater. Lett. 157, 295 (2015). 